\title{
Unresectable Sarcoma
}

National Cancer Institute

\section{Source}

National Cancer Institute. Unresectable Sarcoma. NCI Thesaurus. Code C148331.

A sarcoma which is not amenable to surgical resection. 